\title{
Sudden unexpected death in a mouse model of Dravet syndrome
}

\author{
Franck Kalume, ${ }^{1}$ Ruth E. Westenbroek, ${ }^{1}$ Christine S. Cheah, ${ }^{1}$ Frank H. Yu, ${ }^{1}$ \\ John C. Oakley, ${ }^{1,2}$ Todd Scheuer, ${ }^{1}$ and William A. Catterall ${ }^{1}$
}

1Department of Pharmacology and 2Department of Neurology, University of Washington, Seattle, Washington, USA.

\begin{abstract}
Sudden unexpected death in epilepsy (SUDEP) is the most common cause of death in intractable epilepsies, but physiological mechanisms that lead to SUDEP are unknown. Dravet syndrome (DS) is an infantile-onset intractable epilepsy caused by heterozygous loss-of-function mutations in the SCN1A gene, which encodes brain type-I voltage-gated sodium channel $\mathrm{Na}_{\mathrm{v}} 1.1$. We studied the mechanism of premature death in Scn1a heterozygous $\mathrm{KO}$ mice and conditional brain- and cardiac-specific KOs. Video monitoring demonstrated that SUDEP occurred immediately following generalized tonic-clonic seizures. A history of multiple seizures was a strong risk factor for SUDEP. Combined video-electroencephalography-electrocardiography revealed suppressed interictal resting heart-rate variability and episodes of ictal bradycardia associated with the tonic phases of generalized tonic-clonic seizures. Prolonged atropine-sensitive ictal bradycardia preceded SUDEP. Similar studies in conditional KO mice demonstrated that brain, but not cardiac, KO of Scn1a produced cardiac and SUDEP phenotypes similar to those found in DS mice. Atropine or $\mathrm{N}$-methyl scopolamine treatment reduced the incidence of ictal bradycardia and SUDEP in DS mice. These findings suggest that SUDEP is caused by apparent parasympathetic hyperactivity immediately following tonic-clonic seizures in DS mice, which leads to lethal bradycardia and electrical dysfunction of the ventricle. These results have important implications for prevention of SUDEP in DS patients.
\end{abstract}

\section{Introduction}

Most people with epilepsy live a full life span, but some people with this condition die abruptly without warning or other apparent medical cause. These premature deaths are tragic, devastating outcomes, referred to as sudden unexpected death in epilepsy (SUDEP). Epidemiological studies have estimated that such sudden and unexpected deaths occur up to 40 times more frequently in patients with epilepsy than in the general population (1-3). SUDEP is the leading cause of death in patients with refractory epilepsies and accounts for $40 \%-50 \%$ of mortality $(3,4)$, but the physiological mechanisms that contribute to SUDEP are unknown.

Dravet syndrome (DS) is a drug-resistant and life-threatening epileptic encephalopathy with childhood onset. At least $80 \%$ of cases are associated with heterozygous loss-of-function mutations in the exons of SCN1A, which encodes the brain type-I voltage-gated sodium channel $\mathrm{Na}_{V} 1.1$ (5). DS begins in the first year of life, with fever- or temperature-sensitive seizures that often evolve into refractory generalized tonic-clonic seizures. Affected children develop several comorbid conditions, including psychomotor regression, ataxia, sleep disturbance, and cognitive impairments, and die prematurely with unusually high frequency for a childhood epilepsy syndrome $(6,7)$. High mortality rate is an important feature of the long-term perspective of DS and an issue of serious concern among DS patients, their families, and doctors $(6,8-12)$. A leading hypothesis suggests that SUDEP is due to cardiorespiratory defects (13), but no direct experiments have addressed this possibility in DS.

Because $\mathrm{Na}_{V} 1.1$ channels are expressed in mammalian heart as well as brain (14-18), we have tested the hypothesis that cardiac dysfunction may cause SUDEP in DS using mouse genetic models

Conflict of interest: The authors have declared that no conflict of interest exists. Citation for this article: J Clin Invest. 2013;123(4):1798-1808. doi:10.1172/JCI66220. of this epilepsy in which $\mathrm{Na}_{V} 1.1$ channels are deleted either globally or conditionally in brain or heart. Our original mouse model, generated by global heterozygous $\mathrm{KO}$ of $\operatorname{Scn} 1 a$, develops several key phenotypic features of DS, including epilepsy with early onset (beginning at P21), high susceptibility to hyperthermia-induced seizures, ataxia, spontaneous seizures with age-dependent severity, sleep and circadian abnormalities, and premature deaths (19-25). We performed simultaneous video-EEG-ECG recordings on these mice and discovered interictal, periictal, and ictal abnormalities of neural regulation of the heart associated with their $\operatorname{Scn} 1$ a mutation and with SUDEP susceptibility. Cre-mediated conditional heterozygous deletion of Scn1a in GABAergic forebrain interneurons reproduced the premature deaths and other physiological characteristics of DS, whereas heterozygous cardiac-specific mutation of Scn1a had no effect. Treatment with the muscarinic antagonist atropine or the peripherally restricted muscarinic antagonist $\mathrm{N}$-methyl scopolamine corrected the abnormalities of cardiac regulation and prevented SUDEP. Based on these studies, we propose the hypothesis that seizure-associated episodes of bradycardia caused by hyperactivity of the parasympathetic nervous system are a primary factor causing SUDEP in DS mice. These results suggest that implantable pacemakers might be effective in reducing SUDEP in DS.

\section{Results}

Circumstances of SUDEP in DS mice. To the best of our knowledge, there are no detailed descriptions of the circumstances of SUDEP in DS patients because these tragic events usually occur unexpectedly and unwitnessed $(6,8-12)$. Our previous studies have shown that many of our DS mice die in their fourth postnatal week of life (22). To examine the circumstances of these sporadic deaths, continuous video recordings of 39 DS mice in their home cages were made from P25 to P28. During this monitoring period, 18 mice died and review 
A
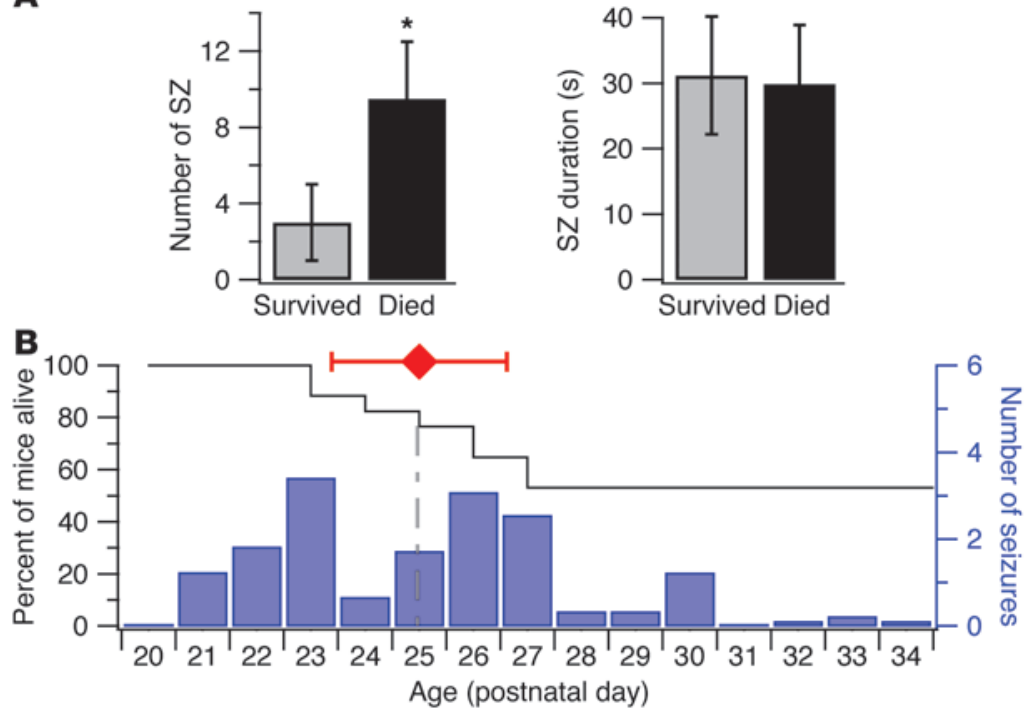

C

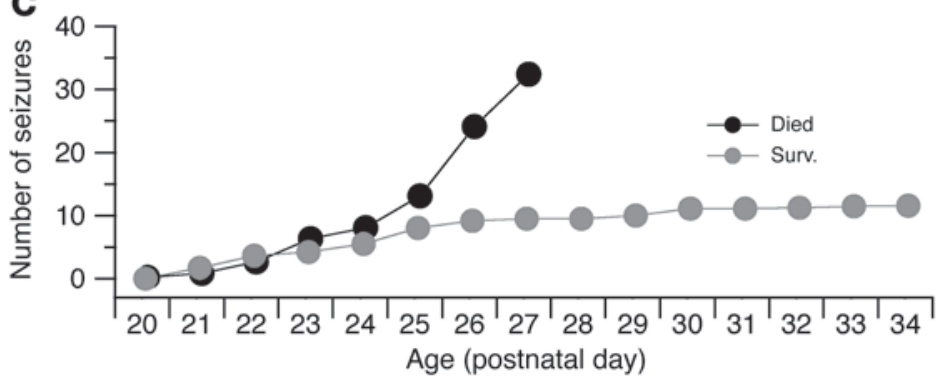

\section{Figure 1}

Spontaneous seizures and sudden unexpected deaths in DS mice. (A) Incidence and duration of spontaneous generalized tonic-clonic convulsions 24 hours prior to death. Continuous short-term videos of DS mice in home cages were collected from P25 to P28. Times of death and convulsions in the 24 hours prior to each death were identified during off-line visual inspection of records. Incidence and duration of convulsions were calculated. Left bar graph illustrates higher incidence of seizures observed in mice that died $(9.5 \pm 3$ seizures $)$ than in those that survived $(3 \pm 2$ seizures, $P<0.05)$. Right graph shows seizure durations $(31.2 \pm 9 \mathrm{~s}$ in mice that died vs. $29.9 \pm 9 \mathrm{~s}$ in mice that survived, $P>0.05$ ). ${ }^{\star} P<0.05$. Data are mean \pm SD. (B) Survival plot (black line, left axis) and bar graph of daily convulsion incidence (right axis) in DS mice illustrating higher mortality and convulsion incidence in the fourth postnatal week of the mice. Continuous long-term videos of DS mice in home cages were collected from P20 to P34. Deaths and convulsions were identified during off-line inspections of records. Daily number of fatalities and seizure incidence were counted. (C) Graph of cumulative numbers of convulsions in mice studied in $\mathbf{B}$ showing a history of elevated number of convulsions experienced by mice that died sporadically during the monitoring period (P20-P34) than by those that survived. of the video records revealed that all the deaths occurred immediately following a Racine 5 generalized tonic-clonic seizure. Analyses of the data indicated that in the 24 hours prior to death, the incidence of convulsive seizures was higher in the mice that died than in those that survived (Figure 1A). However, the Racine score of each seizure was 5.0, and durations of these convulsions were not statistically different between the 2 groups of mice (Figure 1A). These findings indicate that SUDEP is a seizure-induced event and that high incidence of Racine 5 seizures predicts SUDEP susceptibility in these mice, whereas seizure duration does not.

Correlation between epilepsy and premature death in DS mice. To examine the long-term relationship between epilepsy phenotype and SUDEP, 2-week video records of 17 DS mice were obtained during P20-P34. Consistent with our previous findings (22), spontaneous seizures began at P20-P21. Of 17 mice monitored, 6 (35.3\%) died during these recordings. A Kaplan-Meier plot of deaths reveals a correlation of premature death with seizure incidence in postnatal week 4 (P21-P28; Figure 1B), and all of the deaths occurred during the period of highest seizure incidence, P23-P27 (Figure 1B). The elevated cumulative incidence of seizures during postnatal week 4 corresponded to the period of high SUDEP susceptibility, and surviving mice had a much lower frequency of seizures than those that died prematurely (Figure 1C). Status epilepticus, defined as a single seizure or series of recurring seizures lasting more than 30 minutes (26), is an exclusion criterion for the definition of SUDEP in patients $(27,28)$. In our recordings, 3 mice with status epilepticus were identified and excluded from SUDEP analyses. These mice had numerous recurring brief convulsions: 1.5 seizure $/ \mathrm{min}$ in the first 30 minutes and 0.4 seizure/ $\mathrm{min}$ in the following hour.
All 3 mice survived the status epilepticus but died $8 \pm 3$ hours later. Together, these findings indicate a strong correlation between seizure history and deaths in DS mice.

Heart rate in DS, Dlx-Cre, and Mer-Cre mice. $\mathrm{Na}_{V} 1.1$ channels are expressed in mouse brain and heart, and they play critical roles in the function of these organs (14-18). To investigate whether global heterozygous $\mathrm{KO}$ of $\mathrm{Na}_{V} 1.1$ channels in DS mice causes cardiac defects that may predispose to SUDEP, we studied DS mice, heterozygous $\mathrm{F} /{ }^{+}: \mathrm{Dlx}-\mathrm{Cre}^{+}$mice in which $\mathrm{Na}_{v} 1.1$ channels are selectively deleted in forebrain GABAergic interneurons (25), and heterozygous $\mathrm{F} /{ }^{+}: \mathrm{MCre}^{+}$mice in which $\mathrm{Na}_{V} 1.1$ channels are selectively deleted in the heart (Methods). Extensive immunocytochemical studies with specific antibodies demonstrated up to $50 \%$ reduced expression of $\mathrm{Na}_{V} 1.1$ channels in GABAergic interneurons in many regions of the cerebral cortex and hippocampus in $\mathrm{F}^{+}$: $\mathrm{Dlx}-\mathrm{Cre}^{+}$mice, but no reduction in excitatory neurons in these brain regions (25). Similarly, we found that $\mathrm{F} /{ }^{+}: \mathrm{MCre}^{+}$mice have reduced expression of $\mathrm{Na}_{V} 1.1$ channels in the ventricles of the heart (55\% of control; Supplemental Figure 1; supplemental material available online with this article; doi:10.1172/JCI66220DS1).

Continuous 8-hour video-EEG-ECG records were obtained from conscious unrestrained DS, $\mathrm{F} /{ }^{+}: \mathrm{Dlx}-\mathrm{Cre}^{+}, \mathrm{F} /{ }^{+}: \mathrm{MCre}^{+}$, and WT mice from 8:00 am to 4:00 $\mathrm{pm}$. Assessment of the resting heart rates indicated that $\mathrm{DS}$ and $\mathrm{F} /{ }^{+}: \mathrm{Dlx}-\mathrm{Cre}^{+}$mice have slightly elevated, but not significantly different, resting heart rates compared with control mice (Figure 2, A and B, and Supplemental Table 1). F/ ${ }^{+}: \mathrm{MCre}^{+}$mice have significantly suppressed resting heart rate. These findings indicate that global heterozygous $\mathrm{KO}$ of $\mathrm{Na}_{\mathrm{V}} 1.1$ and forebrain inter- 
A

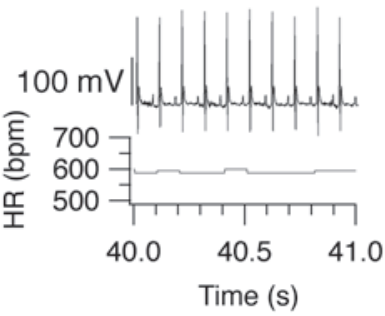

DS

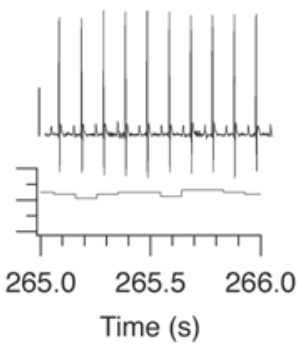

$\mathrm{F}^{++}: \mathrm{DlxCre}^{+}$
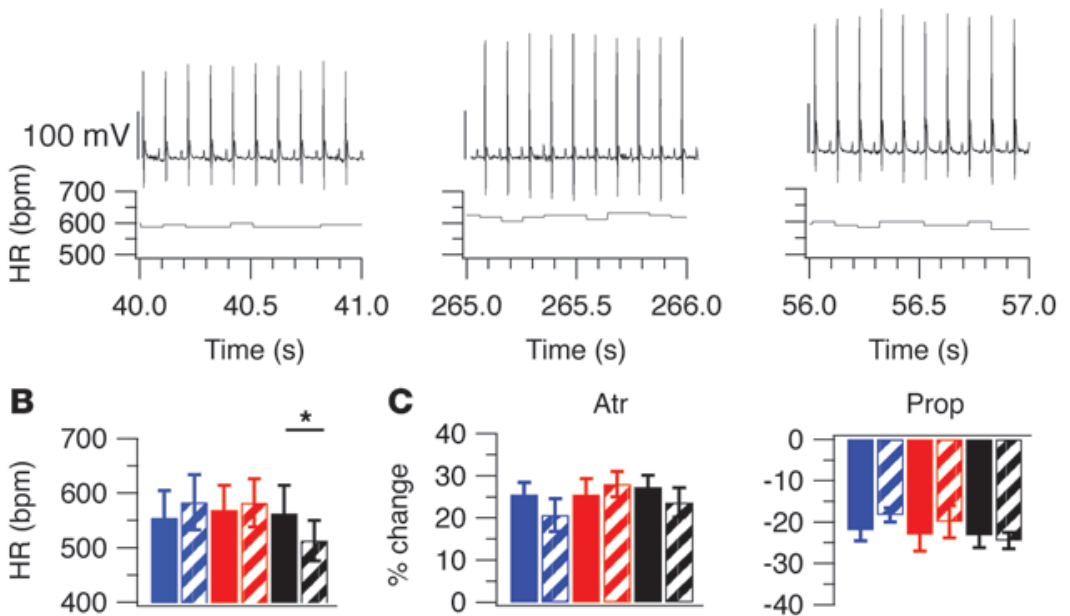

D

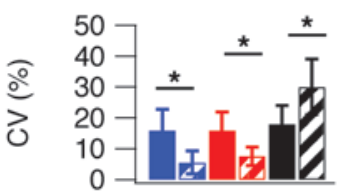

Atr

C

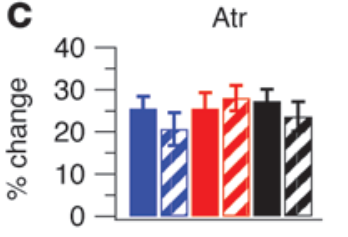

E

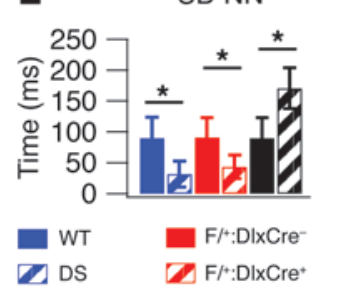

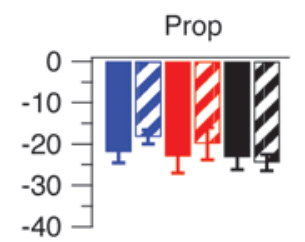

F

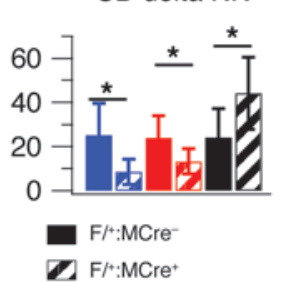

$\mathrm{F}^{++}: \mathrm{MCre}^{+}$

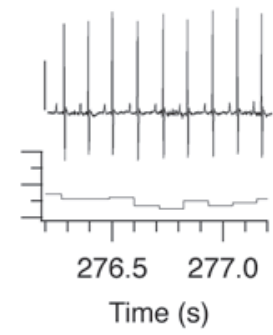

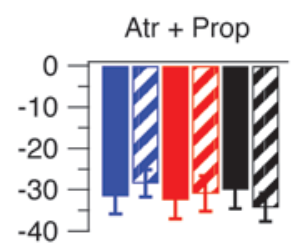

G

RMSSD

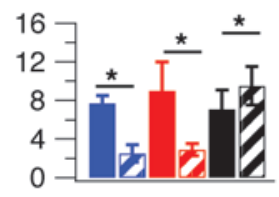

\section{Figure 2}

Cardiovascular effects of global or conditional KO of Scn1a. (A) Representative resting ECG traces with computed instantaneous heart rates. ECG traces were collected during 8-hour video-EEG-ECG recordings, and stable segments devoid of movement artifacts, electrical noise, ectopic beats, or arrhythmias were analyzed. (B) Resting heart rates (HR) calculated from the same ECG records used in A. (C) Change in resting heart rate (\%) after acute i.p. administration of atropine (atr) $(1 \mathrm{mg} / \mathrm{kg})$, propranolol (prop) $(4 \mathrm{mg} / \mathrm{kg}$ ), and combined atropine (1 mg/kg) plus propranolol $(4 \mathrm{mg} / \mathrm{kg})$. Continuous video-EEG-ECG records were obtained before, during, and after drug treatment. Peak effects on ECG were observed around 30 minutes after injection. (D-G) Bar graphs of indices of resting heart-rate variability in Scn1a KO mice and their respective controls. The values of the coefficients of variation of resting heart rate (HR CV) (D), SD of normal R-R intervals (SD NN) (E), SD of $\delta$ NN (F), and root mean square of differences between adjacent normal R-R intervals (RMSSD) (G) were depressed for DS and F/+:Dlx-Cre+ mice but elevated values for $\mathrm{F} /+$ :MCre ${ }^{+}$mice. These indices were calculated from the same records used in $\mathbf{A} .{ }^{*} P<0.05$.

neuron-specific heterozygous $\mathrm{KO}$ of this channel has little or no effect on resting heart rate, whereas cardiac-specific heterozygous $\mathrm{KO}$ of these channels has a suppressive effect on resting heart rate.

Heart rate is controlled primarily by input from the parasympathetic and sympathetic nervous systems to the sino-atrial node of the heart. To examine whether Scn1a KO in DS mice altered resting parasympathetic or sympathetic tone, the effects of pharmacological blockade of each of these branches of the autonomic nervous system were assessed. To differentiate effects due to brain-specific versus cardiac-specific gene $\mathrm{KO}$, similar pharmacological tests were performed in $\mathrm{F} /{ }^{+}: \mathrm{Dlx}-\mathrm{Cre}^{+}$and $\mathrm{F} /{ }^{+}: \mathrm{MCre}^{+}$mice and their respective control groups. Administration of a saturating dose of atropine, a muscarinic receptor antagonist that blocks parasympathetic signaling, caused an increase in heart rate in DS, F/ ${ }^{+}: \mathrm{Dlx}-\mathrm{Cre}^{+}$, and $\mathrm{F} /{ }^{+}: \mathrm{MCre}^{+}$mice similar to that found in their respective controls (Figure 2C and Supplemental Table 1). Administration of a saturating dose of propranolol, a $\beta$ adrenergic receptor antagonist that blocks sympathetic signaling, caused a reduction of heart rate in $\mathrm{DS}, \mathrm{F} /{ }^{+}: \mathrm{Dlx}-\mathrm{Cre}^{+}$, and $\mathrm{F} /{ }^{+}: \mathrm{MCre}^{+}$mice similar to that found in the corresponding controls (Figure 2C and Supplemental Table 1). Simultaneous administration of atropine and propranolol also produced decreases in $\mathrm{DS}, \mathrm{F} /{ }^{+}: \mathrm{Dlx}-\mathrm{Cre}^{+}$, and F/+ $\mathrm{MCre}^{+}$mice similar to those found in controls (Figure 2C and Supplemental Table 1). These findings indicate no detectable change in resting autonomic tone or intrinsic heart rate in Scn1a mutant mice.

Heart-rate variability in DS, Dlx-Cre, and Mer-Cre mice. A decrease in heart-rate variability has been associated with higher mortality and an increased incidence of sudden cardiac death (29). It has been observed in some patients with epilepsy and proposed as a risk factor for $\operatorname{SUDEP}(30,31)$. Analyses of heart-rate variability of Scn 1a-KO mice showed that the coefficient of variation of resting heart rate was decreased for DS mice compared with WT and for $\mathrm{F} /{ }^{+}: \mathrm{Dlx}-\mathrm{Cre}^{+}$mice compared with $\mathrm{F} /{ }^{+}: \mathrm{Dlx}-\mathrm{Cre}^{-}$(Figure $2 \mathrm{D}$ ). In contrast, an increase in the coefficient of variation of heart rate was observed for $\mathrm{F} /^{+}: \mathrm{MCre}^{+}$compared with $\mathrm{F} /^{+}: \mathrm{MCre}^{-}$mice (Figure 2D and Supplemental Table 2). These results indicate that heterozygous deletion of $\mathrm{Na}_{V} 1.1$ channels in all cells or only in forebrain GABAergic neurons decreases heart-rate variability, whereas heterozygous deletion in cardiac myocytes increases heart-rate variability.

To further investigate whether DS mice have suppressed heartrate variability, we analyzed the characteristic intervals in the electrocardiogram. The SD of normal R-R intervals (SD NN), the SD of $\delta \mathrm{NN}$, and the root mean square of differences between adjacent 


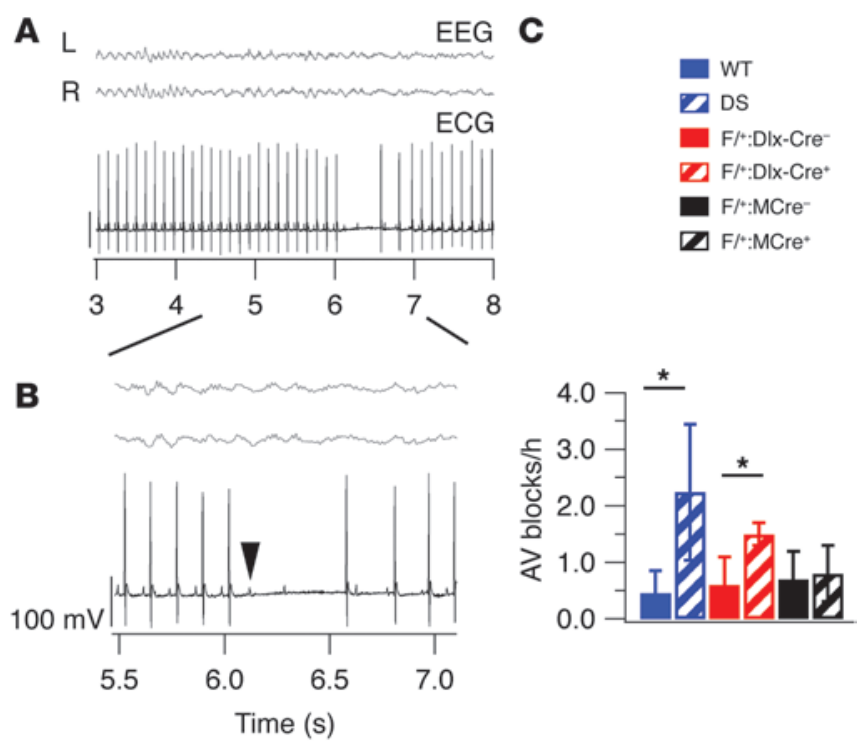

normal R-R intervals (RMSSD) were all reduced in DS mice compared with WT mice (Figure 2, E-G, and Supplemental Table 2). These findings demonstrate that global heterozygous deletion of Scn1a suppresses heart-rate variability in DS mice. Like DS mice, $\mathrm{F} /{ }^{+}:$Dlx-Cre ${ }^{+}$mice had reduced heart-rate variability compared with controls when assessed from measurements of these ECG parameters (Figure 2, E-G, and Supplemental Table 2). In contrast, in $\mathrm{F} /{ }^{+}: \mathrm{MCre}^{+}$mice, all the indices of heart-rate variability were elevated (Figure 2, E-G, and Supplemental Table 2). These findings indicate that global or forebrain interneuron restricted heterozygous deletion of $\mathrm{Na}_{V} 1.1$ channels reduced heart-rate variability, as detected by 4 separate measurements, whereas cardiac-specific heterozygous deletion tends to increase heart-rate variability.

Interictal atrioventricular block in DS mice. The different intervals in the ECG provide a quantitative measure of action potential conduction in the different regions of the heart. No differences were observed in PR, QRS, QT, and corrected QT (QTc) intervals between genotypes, except for a small increase in PR interval in $\mathrm{F} /{ }^{+}: \mathrm{MCre}^{+}$mice (Supplemental Table 3 ). Thus, specific heterozygous deletion of Scn1a in forebrain interneurons does not influence the rate of cardiac conduction, whereas cardiac-specific heterozygous deletion of the gene leads to a small increase in PR interval. Further analysis of the resting ECG records showed a striking increase in the frequency of atrioventricular (AV) block (Figure 3). Transient AV block is common in WT mice, but the frequency was higher in DS mice $(2.24 \pm 1.2 \mathrm{AV}$ blocks $/ \mathrm{h})$ and $\mathrm{F} /{ }^{+}:$Dlx-Cre ${ }^{+}$mice $(1.5 \pm 0.2 \mathrm{AV}$ blocks $/ \mathrm{h})$ compared with their corresponding controls (WT: $0.6 \pm 0.4$ and $\mathrm{F} /{ }^{+}: \mathrm{MCre}^{-}: 0.7 \pm 0.5 \mathrm{AV}$ blocks/h; $P=0.001$ and 0.02 ; Figure 3$)$. In $\mathrm{F} /{ }^{+}: \mathrm{MCre}^{+}$mice, the frequency of AV blocks was slightly elevated $(0.8 \pm 0.5 \mathrm{AV}$ blocks $/ \mathrm{h})$, but not significantly different from control $(0.7 \pm 0.6 \mathrm{AV}$ blocks $/ \mathrm{h}$; $P>0.05$; Figure 3). These findings indicate that global and interneuron-specific heterozygous $\mathrm{KO}$ of $\operatorname{Scn} 1$ a cause a significant increase in the frequency of AV block in DS mice, but targeted cardiac deletion of the gene does not.

Arrbythmias in DS mice during thermal seizure induction. Small elevations of body core temperature reliably induce seizures in DS and $\mathrm{F} /{ }^{+}:$Dlx-Cre ${ }^{+}$mice $(20,25)$. To investigate cardiac function defects associated with generalized tonic-clonic seizures, 1 seizure was

\section{Figure 3}

Frequency of AV block. Increased interictal frequency of AV blocks in DS mice and forebrain interneuron-specific Scn1a-KO $\left(\mathrm{F} /{ }^{+}:\right.$:Dlx-Cre $\left.{ }^{+}\right)$ mice, but not in cardiac-specific Scn1a-KO $\left(\mathrm{F} /{ }^{+}: \mathrm{MCre}^{+}\right)$mice. The 8 hours of continuous video-EEG-ECG recordings were considered for assessments of AV blocks. ECG traces were visually inspected to identify these arrhythmias. (A) Representative simultaneous resting EEG-ECG records from a DS mouse showing regular ECG rhythm and a type-2, second-degree AV block, characterized by skipped QRS complexes without prolongation of preceding PR intervals. All preceding PR intervals in this figure had identical duration, 30.9 ms. (B) Magnified segments of the traces in A. Arrowhead indicates an example of a P wave. (C) Bar graph of interictal AV block frequencies in Scn1a mutant mice and respective control mice illustrating higher frequency of AV blocks in DS (2.24 \pm 1.2 vs. $0.6 \pm 0.4 \mathrm{AV}$ blocks/h in controls) and $\mathrm{F} /+$ :Dlx-Cre ${ }^{+}$mice $(1.5 \pm 0.2 \mathrm{AV}$ blocks/h vs. $0.7 \pm 0.5 \mathrm{AV}$ blocks $/ \mathrm{h}$ in controls), not in $\mathrm{F} /{ }^{+}: \mathrm{MCre}^{+}$mice $(0.8 \pm 0.5 \mathrm{AV}$ blocks $/ \mathrm{h}$ vs. $0.7 \pm 0.6 \mathrm{AV}$ blocks/h in controls). ${ }^{*} P<0.05$. thermally induced daily in P24-P30 DS mice and P22-P27 F/ ${ }^{+}$:Dlx$\mathrm{Cre}^{+}$mice for up to 4 days, and simultaneous video-EEG-ECG records were obtained. Twenty-three DS mice and $9 \mathrm{~F} /{ }^{+}: \mathrm{Dlx}-\mathrm{Cre}^{+}$ mice were tested, and 82 thermally induced seizures were recorded. Four out of 23 (17.4\%) DS mice and 4 out of 9 (44.5\%) F/ ${ }^{+}: \mathrm{Dlx}^{-C r \mathrm{C}^{+}}$ mice died during these experiments. We first analyzed the combined video-EEG-ECG records of the mice that survived the experiments. The initial seizure discharges observed during elevation of body core temperature were myoclonic seizures, as we reported previously (20). Only a small portion (2 out of 23) of these mice displayed short ECG pauses (likely to be AV blocks) associated with myoclonic seizures. Further increase in temperature induced generalized tonic-clonic seizures (Figure 4A). The EEG-ECG records revealed that DS mice experienced a period of bradycardia at the onset of the generalized tonic-clonic seizures, followed by tachycardia, and a second period of bradycardia at the end of the seizures (Figure 4, A and B). Video records showed that the episodes of bradycardia began at the onsets of the tonic phases of the generalized tonic-clonic seizures (Figure 4A). Despite the striking bradycardia, the QRS duration and R-wave amplitude were not significantly different from control values during bradycardia or tachycardia in the 19 DS mice that did not die (Figure 4C). The marked changes in heart rate point to excessive parasympathetic tone at the onset and end of tonic-clonic seizures and increased sympathetic tone during the tonic-clonic seizures as the major contributing factors to changes in cardiac function. The episodes of bradycardia were correlated with the tonic phase of the seizures.

Arrbythmia in DS mice that died during thermally induced seizures. As indicated above, a portion of DS mice $(4 / 23)$ and $\mathrm{F} /{ }^{+}: \mathrm{Dlx}-\mathrm{Cre}^{+}$mice (4/9) died during thermal seizure induction following a generalized tonic-clonic seizure. Each of these mice survived at least 1 thermal seizure induction before death. To examine whether seizure severity predicted susceptibility to death, the duration and Racine score of the fatal and nonfatal seizures were compared in each animal. In DS mice, both fatal and nonfatal seizures were of Racine 5 severity and had similar durations (Figure $5, \mathrm{~A}$ and $\mathrm{B}$ ). In $\mathrm{F} /{ }^{+}$: $\mathrm{Dlx}-\mathrm{Cre}^{+}$mice, the fatal seizures were more severe than the nonfatal ones (Racine $5.0 \pm 0$ vs. $3.5 \pm 1.0, n=4 ; P=0.001$ ), but the duration periods of the 2 types of seizures were not different (Figure 5B). 
A

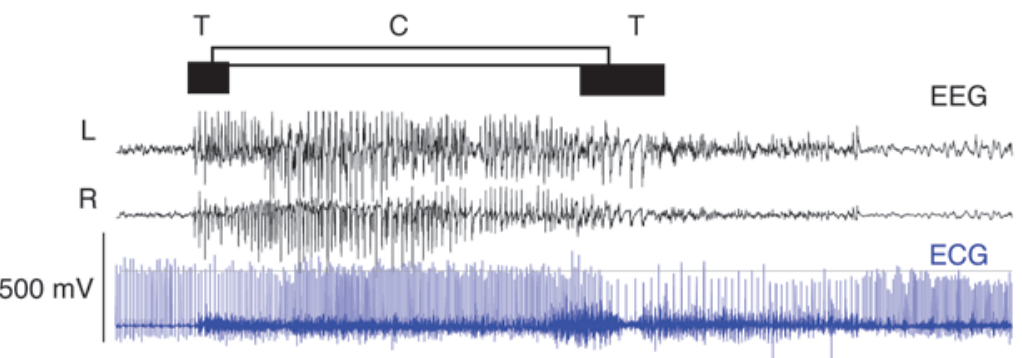

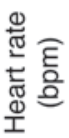

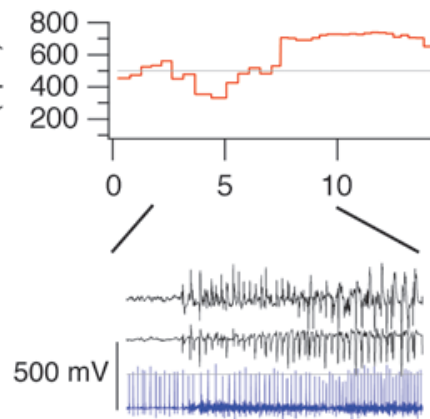

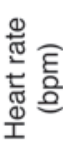

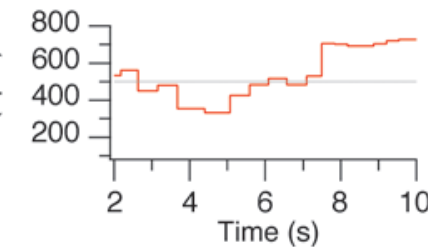

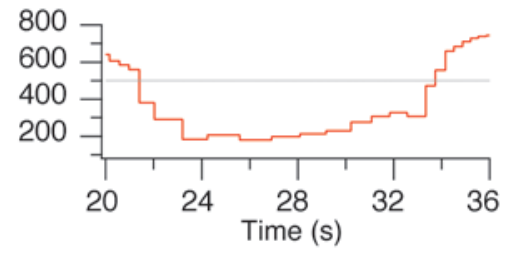

B

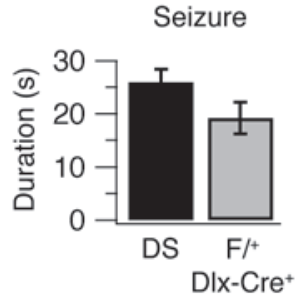

C

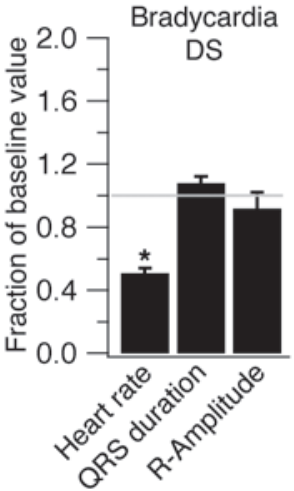

Bradycardia

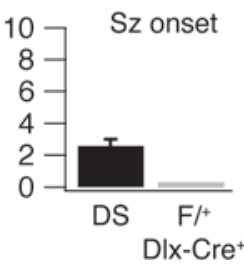

Tachycardia

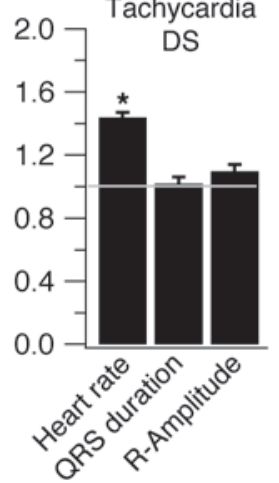

Bradycardia

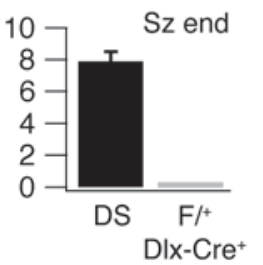

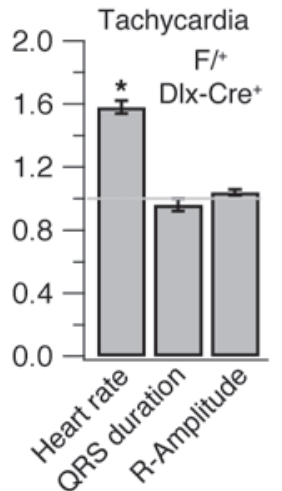

\section{Figure 4}

Thermally induced seizures and bradycardia. Continuous video-EEG-ECG records were obtained before, during, and after thermal seizure inductions in $\mathrm{DS}$ and $\mathrm{F} /+: \mathrm{Dlx}^{-} \mathrm{Cre}^{+}$mice as described in Methods. (A) Representative combined EEG-ECG records (black, blue) and computed instantaneous heart rate (red). The seizure was characterized by generalized spike-and-wave discharges and Racine 5 generalized tonic-clonic convulsions observed on video. Bradycardia was defined by a fall of instantaneous heart rate more than $1 \mathrm{SD}$ below the mean (gray line). Tachycardias were defined by a rise of instantaneous heart rate more than $1 \mathrm{SD}$ above the mean. Horizontal bars indicate the tonic $(T)$ and clonic $(C)$ phases of the seizure. (Lower traces) Magnified segments of records containing ictal bradycardias. (B) Seizure and bradycardia durations in 19 DS mice (black) and $5 \mathrm{~F} /+$ :Dlx-Cre ${ }^{+}$(gray) mice that did not die. Left shows seizure (sz) durations: $26 \pm 2.4 \mathrm{~ms}$ for deaths; $19.2 \pm 3.0 \mathrm{~ms}$ for survivors. Middle and right show bradycardia durations: $2.6 \pm 0.4 \mathrm{~ms}$, seizure onset; $7.9 \pm 0.6 \mathrm{~ms}$, seizure termination in survivors. No bradycardia was observed in $\mathrm{F} /+$ :Dlx-Cre ${ }^{+}$survivors. (C) Fractional changes in ECG intervals caused by thermal seizures in 19 DS (black) and $5 \mathrm{~F} /+$ :Dlx-Cre ${ }^{+}$(gray) survivors, calculated as ratio of ictal bradycardia/baseline values. Left shows bradycardia in DS mice. QRS duration, $1.08 \pm 0.04 ; R$ wave amplitude, $0.92 \pm 0.1$. Middle shows tachycardia in DS mice. QRS duration, $1.02 \pm 0.04$; R-wave amplitude, $1.1 \pm 0.04$. Right shows tachycardia in $\mathrm{F} /+$ :Dlx-Cre ${ }^{+}$mice. QRS duration, $0.96 \pm 0.04$; $R$ wave amplitude, $1.04 \pm 0.02$. No bradycardia was observed in $\mathrm{F}^{++}$:Dlx-Cre+ ${ }^{+}$survivors. ${ }^{*} P<0.05$.
To investigate the functional defects that predict death, the EEG and ECG records of DS and $\mathrm{F} /{ }^{+}: \mathrm{Dlx}-\mathrm{Cre}^{+}$mice that succumbed during these experiments were evaluated. The time of death in these records was defined as the point of cessation of cerebral electrical activity, when the total power of the EEG dropped to zero. This also corresponded to the time of cessation of all movements, including respiration. The duration of episodes of ictal bradycardia was longer in mice that died compared with those that survived for both DS mice and F/+:Dlx-Cre ${ }^{+}$mice (Figure 5B).
To examine whether ictal bradycardia preceding death was accompanied by impaired cardiac conductance, changes in the indices of cardiac conduction during seizure and during resting behavior 30 minutes before seizure induction were examined. During nonfatal bradycardia in DS mice, the QRS duration increased without change in R-wave amplitude (Figure $5 \mathrm{C}$ ). In $\mathrm{F} /{ }^{+}: \mathrm{Dlx}-\mathrm{Cre}^{+}$mice, no bradycardia was observed in nonfatal seizures (Figure $5 \mathrm{~B}$ ). For fatal bradycardia in DS mice, the QRS duration was significantly increased and the R-wave amplitude was significantly reduced 

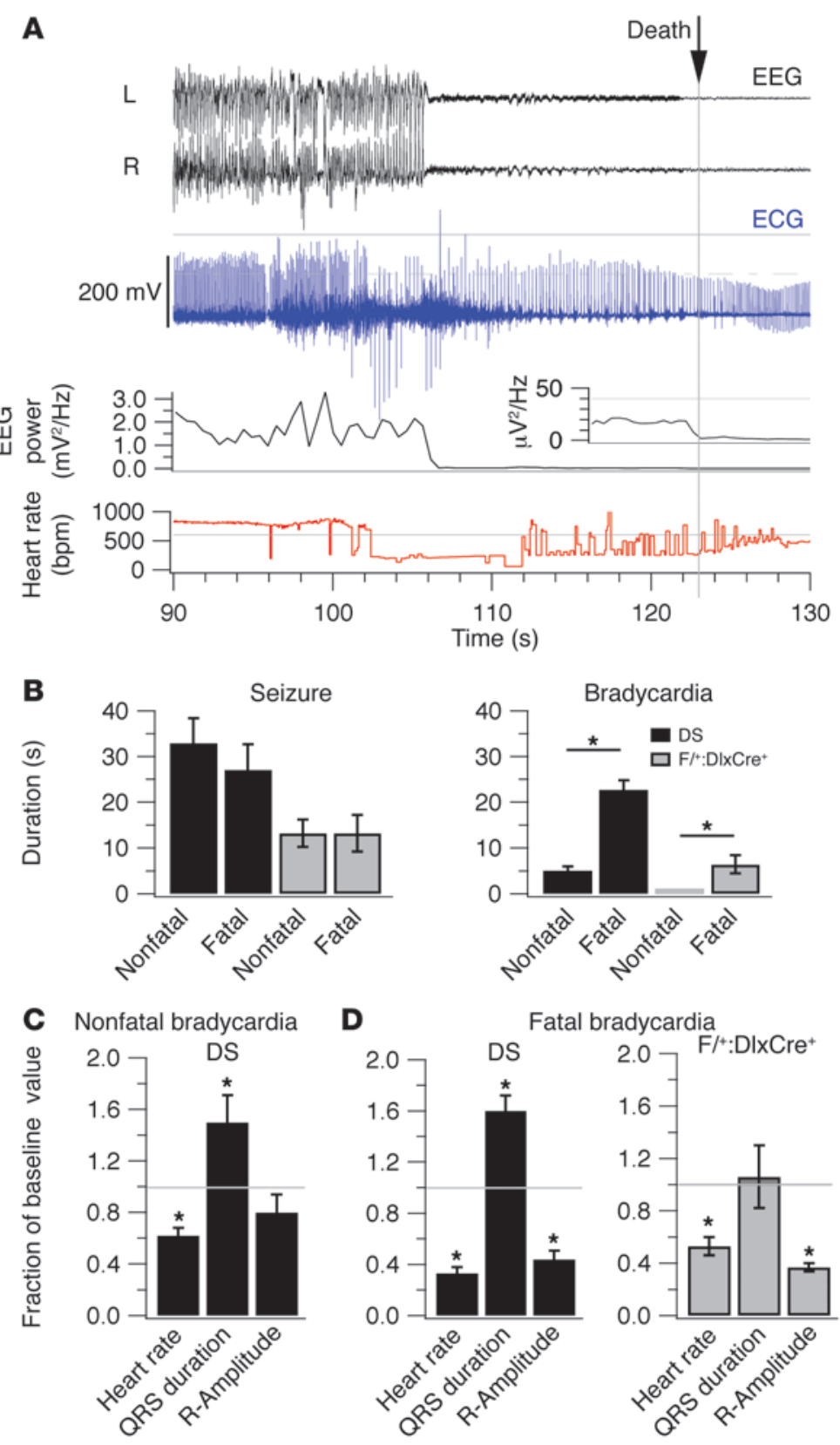

D
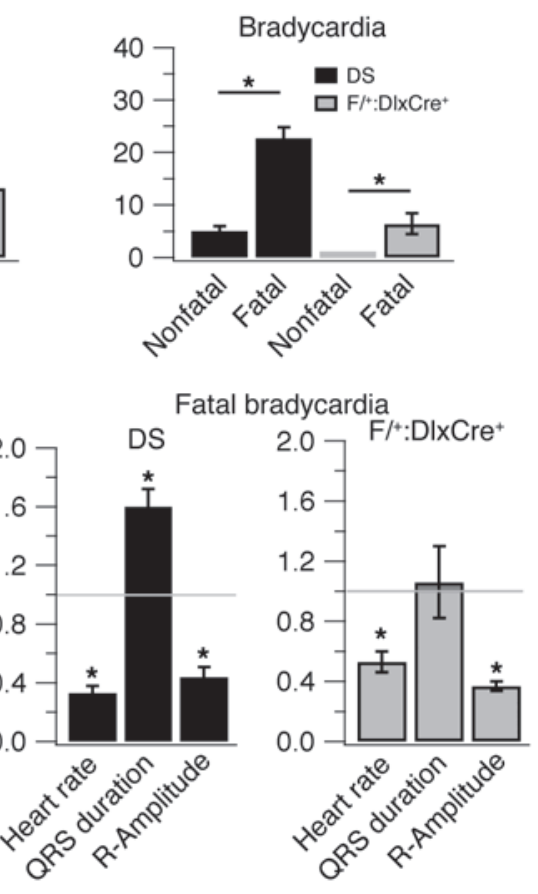

Figure 5

Ictal bradycardia and premature death. (A) Representative traces of EEG-ECG records (black, blue), instantaneous heart rate, and instantaneous EEG power before death, illustrating the seizure and bradycardia preceding death. Time of death was defined as the moment when the power of the EEG fell to zero value, which coincided with cessation of ambulatory and respiration movements. Inset shows magnification of power trace below. (B) Left shows seizure durations in $4 \mathrm{DS}$ (black) and $4 \mathrm{F/+}:$ Dlx-Cre ${ }^{+}$mice (gray) that died. In DS mice, the duration of seizures was $32.9 \pm 5.5 \mathrm{~ms}$ for fatal seizures vs. $27.1 \pm 5.6 \mathrm{~ms}$ for nonfatal seizures $(P>0.05)$. In $\mathrm{F} /+$ :Dlx-Cre ${ }^{+}$mice, duration was $13.2 \pm 3.0$ for fatal seizures vs. $13.2 \pm 4.0 \mathrm{~ms}$ for nonfatal $(P>0.05)$. Right shows bradycardia duration. DS mice, $22.8 \pm 2.0 \mathrm{~ms}$ in fatal seizures vs. $5.1 \pm 1.0 \mathrm{~ms}$ in nonfatal ones; $\mathrm{F} /+$ :Dlx-Cre ${ }^{+}$mice, no nonfatal seizures; bradycardia duration for fatal seizures, $6.4 \pm 2.0 \mathrm{~ms}$. (C) Fractional changes in ECG parameters during nonfatal bradycardia in DS mice $(n=4)$, calculated as the ratio ictal bradycardia/baseline. (D) Fractional changes in ECG parameters in fatal bradycardia. Left shows DS mice $(n=4)$. Right shows $\mathrm{F} /+$ :Dlx-Cre ${ }^{+}$mice $(n=4) .{ }^{*} P<0.05$.
(Figure 5D), whereas in $\mathrm{F}^{+}:$Dlx-Cre ${ }^{+}$mice, the QRS duration was unchanged but the R-wave amplitude was significantly reduced (Figure 5D).

Reduced incidence of SUDEP after treatment with atropine and $N$-methyl scopolamine. To examine whether the periodic ictal bradycardias in DS mice are due to activation of parasympathetic input to the heart, 5 DS mice implanted with EEG and ECG electrodes were tested on 3 consecutive days with an acute i.p. injection of saline on the first day, atropine $(1 \mathrm{mg} / \mathrm{kg})$ on the second day, and saline on the third day. On each day, 30 minutes after injection, mice were subjected to the thermal seizure induction protocol, and concurrent video-EEG-ECG recordings were carried out. All of the mice had ictal bradycardia during saline treatment, but treatment with atropine prevented bradycardia in all of the mice (Figure 6A). This effect was reversible after wash-out of the drug. Similar experiments showed that treatment with propranolol $(1 \mathrm{mg} / \mathrm{kg}$, i.p.) did not eliminate the bradycardia in all 5 DS mice tested (Figure 6B), but combined treatment of atropine and propranolol eliminated bradycardia in all DS mice treated (Figure 6C). These findings indicate that ictal bradycardia is caused by hyperactivation of parasympathetic input to the heart.

To examine the cause-and-effect relationship between ictal bradycardia and SUDEP, 15 DS mice were chronically treated with atropine via an osmotic pump $(10 \mathrm{mg} / \mathrm{kg} /$ day $)$ during the age period of their highest incidence of SUDEP (P21-P28), and 20 DS mice were similarly treated with saline for control. Atropine treatment greatly reduced SUDEP compared with controls (Figure 6E). This finding illustrates the efficacy of chronic treatment with atropine in preventing SUDEP in DS mice. We also tested the effect of acute treatment with atropine in $\mathrm{F} /{ }^{+}: \mathrm{Dlx}-\mathrm{Cre}^{+}$mice, which always die following thermally induced Racine 5 generalized seizures. Acute atropine treatment allowed all $5 \mathrm{~F} /{ }^{+}: \mathrm{Dlx}-\mathrm{Cre}^{+}$ mice studied to survive Racine 5 generalized seizures. Together, these results indicate that prevention of hyperstimulation of the heart by the parasympathetic nervous system is sufficient to prevent ictal bradycardia and SUDEP in these mouse models of DS.

Atropine exerts both central and peripheral antimuscarinic actions. To ensure that the reduced incidence of SUDEP in DS mice treated with atropine is due to cardiac and not central action of the drug, mice were treated with $\mathrm{N}$-methyl scopolamine, a muscarinic receptor antagonist that does not cross the blood-brain barrier, in both acute and chronic experiments as above. Acute administration of $\mathrm{N}$-methyl scopolamine $(1 \mathrm{mg} / \mathrm{kg}$, i.p.) eliminated the bradycardia associated with thermally induced seizures in all 10 treated DS mice (Figure 6D). Chronic treatment with the drug (10 mg/kg/day, osmotic pump), in the fourth week of life substantially reduced the incidence of deaths in DS mice compared with control saline treatment (Figure 6E). These findings indicate that peripheral blockade of muscarinic receptors is sufficient to reduce SUDEP in DS mice. 

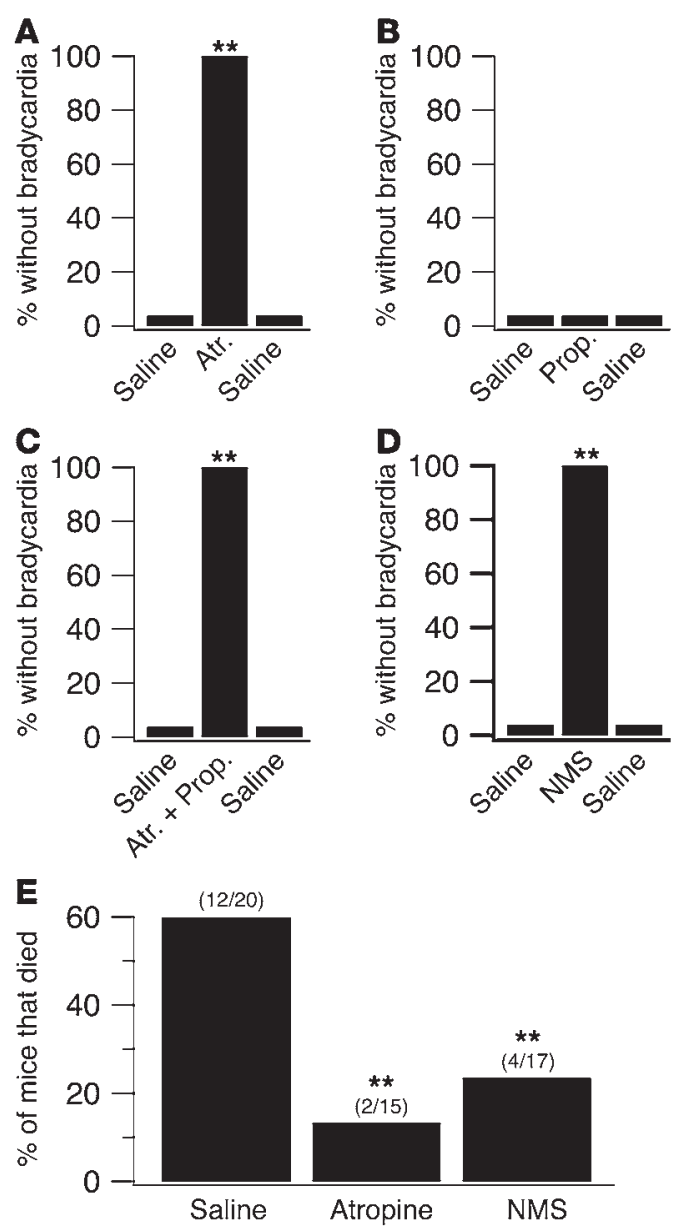

\section{Discussion}

Using genetic mouse models, we investigated the cardiac functional defects that underlie SUDEP in DS, an epilepsy syndrome associated with an unusually high incidence of sudden deaths. As developed in more detail in the sections below, our results indicate that SUDEP in DS mice results from ictal and postictal dysregulation of the heart via hyperactivity of the parasympathetic nervous system, which causes death by inducing severe bradycardia and associated alterations in ventricular electrical function. Because DS shares similar mechanisms of pathogenesis with other SCN1Aassociated epilepsies, we predict that SUDEP in other epilepsies such as generalized epilepsy with febrile seizures plus (GEFS ${ }^{+}$) (32) may arise from similar mechanisms.

Reduced heart-rate variability and episodes of bradycardia in DS mice. Our results show that DS mice have 2 abnormalities of control of the heart under resting conditions - reduced heart-rate variability and frequent episodes of AV block. The reduced heart-rate variability during interictal resting periods in DS mice indicates that an underlying failure of cardiac regulation is caused by the Scn1a mutation. The elevated frequency of AV blocks in DS mice during their period of sleep in daytime also indicates a failure of normal cardiac regulation under resting conditions. These abnormalities are not observed in $\mathrm{F} /{ }^{+}: \mathrm{MCre}^{+}$mice, which have a specific deletion of $\mathrm{Na}_{\mathrm{V}} 1.1$ channels in the heart; therefore, these defects in cardiac regulation must arise outside the heart. Both of these defects result most likely from abnormal regulation by the parasympa-

\section{Figure 6}

Effects of atropine and $\mathrm{N}$-methylscopolamine on bradycardia and death. Thermal seizures were induced in DS mice treated with autonomic nervous system blockers, and ECG traces were examined for ictal bradycardia. (A) DS mice without ictal bradycardia (\%) after acute i.p. treatment with saline, atropine $(1 \mathrm{mg} / \mathrm{kg})$, or saline on 3 consecutive days. (B) DS mice without ictal bradycardia (\%) after acute i.p. treatment with saline, propranolol $(4 \mathrm{mg} / \mathrm{kg})$, or saline on 3 consecutive days. (C) DS mice without ictal bradycardia (\%) after acute i.p. treatment with saline, atropine plus propranolol, or saline on 3 consecutive days. (D) DS mice without ictal bradycardia (\%) after acute i.p. treatment with atropine, N-methyl scopolamine (NMS), or saline on 3 consecutive days. (E) DS mice that died sporadically (\%) during chronic treatment with atropine, NMS, or saline via osmotic pump from P21-P28. ${ }^{* *} P<0.01$ ( $\chi^{2}$ test $)$.

thetic nervous system, which exerts primary control on slowing of heart rate and on heart-rate variability. The lack of significant differences in change of resting heart rate in response to atropine, propranolol, or a combination of the 2 drugs in DS mice indicates that the resting parasympathetic and sympathetic tones remained unaltered in DS mice, even though neural regulation of heart-rate variability was impaired.

Functional roles of $N a_{V} 1.1$ channels in the heart. Our studies of $\mathrm{F} /{ }^{+}: \mathrm{MCre}^{+}$mice reveal specific functional effects of deletion of $\mathrm{Na}_{V} 1.1$ channels in the heart itself, including reduced heart rate, increased PR interval, and increased heart-rate variability. In previous studies, we found that selective inhibition of $\mathrm{Na}_{V} 1.1$ channels in mouse heart with low concentrations of tetrodotoxin caused reduced heart rate and increased heart-rate variability (14). As expected from that work, $\mathrm{F} /{ }^{+}: \mathrm{MCre}^{+}$mice also have a significant reduction in heart rate and a significant increase in heart-rate variability (Supplemental Tables $1-3$ ). These results show that the reduction of $\mathrm{Na}_{V} 1.1$ channels to $55 \%$ of normal in the heart of $\mathrm{F} /{ }^{+}: \mathrm{MCre}^{+}$mice is sufficient to have functional effects on regulation of heart rate, as expected from previous work (14). These changes in intrinsic cardiac function were not observed in DS mice, indicating that they are occluded by the more severe effects of deletion of $\mathrm{Na}_{V} 1.1$ channels in the nervous system. As these changes in intrinsic cardiac function were not observed in DS mice, they cannot contribute to their SUDEP.

SUDEP is associated with repetitive generalized tonic-clonic seizures in DS mice. Video monitoring of DS mice provided direct evidence of a strong temporal correlation between seizures and SUDEP in these mice. All SUDEP observed in DS mice occurred immediately following a generalized tonic-clonic seizure. Because not all such seizures led to death, this finding suggests that a generalized tonic-clonic seizure is an immediate risk factor, not a predictor, for SUDEP in DS mice. The cumulative number of seizures was dramatically elevated in DS mice that died during the fourth postnatal week compared with those that survived. Together, these findings indicate that daily seizure incidence and seizure history are strong risk factors for SUDEP susceptibility in DS mice.

Ictal bradycardia leads to SUDEP in DS mice. The episodes of bradycardia that immediately precede deaths of DS mice following thermally induced seizures suggest that SUDEP in DS mice is caused by this striking ictal bradycardia. However, not all the episodes of bradycardia led to death. Compared with nonlethal bradycardia, lethal episodes of bradycardia had longer duration and more suppressed heart rate, suggesting that these characteristics are predictive of SUDEP. 
These same changes in heart rate in mice that are destined to die are likely to be caused by hyperactivation of parasympathetic input to the heart because they are prevented by atropine and $\mathrm{N}$-methylscopolamine. This apparent hyperactivation of parasympathetic input to the heart could induce ventricular dysfunction by reducing the pacemaking activity in the SA node and blocking conduction in the $\mathrm{AV}$ node, leaving the slower pacemaking activity of the conduction system to drive ventricular action potentials at a slower rate and with less synchrony. Alternatively, severe bradycardia caused by apparent hyperactivation of the parasympathetic input to the heart could lead to transient ischemia in ventricular myocytes, reducing the speed and synchrony of their action potential generation. In either case, severe bradycardia and associated changes in ventricular electrical activity could lead to loss of brain activity and finally cardiac arrest.

The strong temporal association between ictal bradycardia and the tonic phase of the generalized tonic-clonic seizures suggests that these cardiac arrhythmias are caused by the spreading of seizure activity from the forebrain to the brain stem cardioregulatory centers. We observed that deaths of $\mathrm{F} /{ }^{+}: \mathrm{Dlx}-\mathrm{Cre}^{+}$mice that have $\mathrm{Na}_{V} 1.1$ channels specifically deleted in forebrain GABAergic neurons were associated with cardiac dysfunction similar to that found during the death of DS mice. Severe bradycardia and reduced R-wave amplitude were observed immediately preceding the death of $\mathrm{F} /^{+}: \mathrm{Dlx}-\mathrm{Cre}^{+}$mice during thermal seizure-induction experiments, and all F/+:Dlx-Cre ${ }^{+}$mice that had generalized tonic-clonic seizures died. These results show definitively that loss of $\mathrm{Na}_{V} 1.1$ channels in forebrain GABAergic neurons is sufficient to induce bradycardia, ventricular dysfunction, and SUDEP in DS mice.

Our results support the conclusion that loss of $\mathrm{Na}_{\mathrm{v}} 1.1$ channels in forebrain inhibitory neurons leads to tonic-clonic seizures, the tonic phase of seizures leads to bradycardia and altered ventricular electrical function, and together these cardiac defects lead to SUDEP. However, there are potentially important links in this chain of events that remain uncertain. For example, how does failure of firing of GABAergic forebrain interneurons cause hyperactivation of the parasympathetic nervous system? We think it is most likely that descending neural input from the seizure in the cerebral cortex to the vagal motor nucleus in the brain stem causes hyperactivity of the parasympathetic outflow to the heart directly. However, our results do not exclude the possibility that peripheral systemic changes such as metabolic acidosis during seizures might contribute to hyperactivity of the parasympathetic nervous system by a more indirect route via carotid reflexes or other cardiovascular feedback mechanisms. We think this is less likely because metabolic acidosis should worsen with time, yet the duration of seizures that lead to bradycardia and premature death is short $(27 \pm 6 \mathrm{~s}$; Figure $5 \mathrm{~B}$ ) and is not significantly different from the duration of seizures that do not lead to death ( $33 \pm 6 \mathrm{~s}$; Figure $5 \mathrm{~B})$, indicating that there is no positive correlation among seizure duration, bradycardia, and death. Nevertheless, in either case, our results with atropine and $\mathrm{N}$-methylscopolamine directly implicate apparent hyperactivity of the parasympathetic input to the heart as a key link in this lethal chain of events.

Physiological dysfunctions in mouse genetic models of SUDEP. Cardiac dysfunctions that may underlie SUDEP have also been investigated in $\mathrm{K}_{V} 1.1$ homozygous null mice, which exhibit temporal lobe seizures, and in $\mathrm{K}_{V} 7.1$ (KCNQ1) mutant mice that carry cardiac long QT syndrome mutations and experience brief partial seizures $(33,34)$. Patients and mice with long QT syndrome mutations in $K_{V} 7.1$ channels are thought to die of cardiac arrhythmia, not SUDEP. Patients with mutations in $\mathrm{K}_{V} 1.1$ channels have cerebellar ataxia, continuous muscle activity, and epilepsy, but do not die of $\operatorname{SUDEP}(35,36)$. Homozygous $\mathrm{K}_{\mathrm{V}} 1.1 \mathrm{KO}$ mice exhibit interictal AV blocks and bradycardia that are sensitive to atropine $(33,34)$. These cardiac effects are associated with loss of $K_{V} 1.1$ channels in juxtaparanodal regions of myelinated axons of the vagus nerve in $\mathrm{K}_{V} 1.1$ null mice. Moreover, axons of vagus nerve excised from these mice are hyperexcitable in the presence of 4-aminopyridine, a blocker of $K_{V} 1.1$ and $K_{V} 1.2$ channels (37). However, because patients with mutations in $K_{V} 1.1$ channels do not die of SUDEP, the dysfunction of the vagus nerve reported for $\mathrm{K}_{\mathrm{V}} 1.1$ mutations in mice is evidently not sufficient to cause SUDEP when $K_{V} 1.1$ mutations are present in patients. Mice with mutations in $K_{V} 1.1$ channels die prematurely, but only a single example of association between premature death and seizures has been presented (33). Therefore, it seems likely that premature deaths in $\mathrm{K}_{\mathrm{V}} 1.1 \mathrm{KO}$ mice are caused by primary dysfunction of the vagus nerve rather than by hyperactivity induced by seizures.

Our results differ from this previous work in several respects. First, SUDEP is very common in human DS, which is caused by heterozygous loss-of-function mutations in $\mathrm{Na}_{V} 1.1$ channels. DS mice with comparable heterozygous mutations also have frequent SUDEP, and approximately $60 \%$ to $70 \%$ of mice die by P 60 . Second, we report here that all 24 spontaneously occurring premature deaths that we observed immediately followed a Racine 5 generalized tonic-clonic seizure, demonstrating tight linkage of premature death to seizures. Third, using thermal induction of seizures, we found that all seizure-induced deaths were associated with bradycardia that arises during the final tonic convulsion of a generalized tonic-clonic seizure and continues after the seizure until death ensues. The mean time of bradycardia was 26 seconds among mice that died. Thus, seizure-induced bradycardia was prominent in all deaths. Fourth, specific deletion of $\mathrm{Na}_{V} 1.1$ channels in forebrain GABAergic inhibitory neurons in $\mathrm{F} /{ }^{+}$:DlxCre mice is sufficient to cause SUDEP with frequency similar to that found in DS mice. These results indicate that the SUDEP in DS mice is initiated by failure of firing of GABAergic interneurons in the forebrain, and they eliminate dysfunction of the vagus nerve or the neurons of vagal motor nucleus in the brain stem as the site of initiation of SUDEP in this disease model. Finally, we found that prevention of bradycardia by treatment with the muscarinic antagonists atropine, which acts generally, and $\mathrm{N}$-methylscopolamine, which is peripherally restricted, reduces the incidence of spontaneous premature deaths. The effectiveness of peripherally restricted $\mathrm{N}$-methylscopolamine in preventing premature death further supports excessive downregulation of the heart rate by the parasympathetic nervous system as the ultimate pathogenetic event in SUDEP in DS mice. It will be of interest in future studies to pinpoint the neural circuits that conduct the hyperactivity generated by failure of firing of forebrain GABAergic interneurons downward to the vagal motor nucleus in the brain stem and eventually result in hyperactivity of the parasympathetic nervous system, bradycardia, and death.

Respiratory dysfunctions have been proposed as a possible cause of $\operatorname{SUDEP}(1,3,4,13)$, and impaired respiratory function during seizures has been reported in patients who suffered $\operatorname{SUDEP}(38,39)$. DBA-1 and DBA-2 mice, which are susceptible to audiogenic seizures, experience respiratory arrest, followed by cardiac arrest, prior to seizure-induced deaths (40). Such deaths 
could be prevented by treatment of the mice with fluoxetine, a selective serotonin reuptake inhibitor (SSRI) (41). In contrast to DBA mice, respiratory arrest was not observed prior to SUDEP in DS mice; in fact, we observed an increase in respiration rate during convulsions and rapid, shallow breathing postictally. Primary respiratory failure would be accompanied by tachycardia rather than the profound bradycardia that we observe, and lethal sequelae of impaired respiration such as acidosis, hypoxia, and hypercarbia would require longer than the 26-second period of bradycardia that leads to death in DS mice. Our results that specific deletion of $\mathrm{Na}_{V} 1.1$ channels in forebrain GABAergic interneurons in $\mathrm{F} /{ }^{+}: \mathrm{Dlx}-\mathrm{Cre}$ mice is sufficient to cause SUDEP and that SUDEP can be prevented by block of bradycardia with peripherally restricted $\mathrm{N}$-methylscopolamine argue against a primary role for dysfunction of the autonomic nuclei in the brain stem that regulate respiration and other essential functions in causing SUDEP in DS mice. In future studies, it will be of interest to investigate the changes in respiratory function during SUDEP in DS mice more quantitatively to determine whether physiologically significant changes in respiratory function accompany bradycardia-induced sudden death in DS mice.

Clinical implications for SUDEP in DS. Our findings are consistent with indications from human studies of the circumstances of deaths in epilepsy, which indicate association of SUDEP with generalized tonic-clonic seizures $(42,43)$. However, most cases of SUDEP in humans occur unwitnessed in bed, at home, and during the night. The majority of studies that established a correlation between SUDEP and seizures are based on indirect evidence of seizure occurrence near the time of death, such as bitten tongue, urinary incontinence, and disrupted environment. In the few studies of witnessed SUDEP cases, this correlation is based on accounts from friends and family members $(3,13,44,45)$. Our studies of SUDEP in DS mice provide much more direct and clearcut association of SUDEP with seizures in DS because we find that all instances of SUDEP immediately follow a Racine 5 generalized tonic-clonic seizure. As in our studies, the presence of generalized seizures, seizure incidence, seizure history, and age are all proposed as risk factors for SUDEP in DS patients $(3,43,46)$.

Several other aspects of our studies of DS mice also correlate with observations of DS patients. Notably, as in DS mice, Delogu and colleagues (47) found that DS patients have suppressed resting heart-rate variability compared with other epileptic patients or nonepileptic individuals. Similarly, as in DS mice, most SUDEP cases in patients with DS and other types of epilepsy occur in sleep $(9,12,47,48)$. A common factor in SUDEP may therefore be hyperactivation of parasympathetic regulation of the heart, leading to severe bradycardia, electrical dysfunction of the ventricle, cardiac arrest, and death. If bradycardia resulting from apparent hyperactivation of the parasympathetic input to the heart is a critical feature of SUDEP in patients with DS, the incidence of SUDEP might be substantially reduced by use of implantable electrical pacemakers to sustain normal cardiac rhythm through seizures despite hyperactivation of the parasympathetic nervous system.

\section{Methods}

Animals. Mice carrying a global heterozygous KO of $\operatorname{Scn} 1$ a $\left(\operatorname{Scn} 1 a^{+/-}\right.$or DS mice) were generated by targeted gene deletion as previously described by Yu et al. (22). DS mice and littermate controls used in this study were obtained by breeding $\operatorname{Scn} 1 a^{+/-}$males and $\operatorname{Scn} 1 a^{+/+}$females, both from a C57BL/6 genetic background. Mice were genotyped as previously described by Kalume et al. (19). All mice used in this study were pathogen free and housed in the University of Washington Animal Facility at constant $\left(22^{\circ} \mathrm{C}\right)$ temperature, on 12 -hour light/12-hour dark cycles, with ad libitum access to food and water.

Mice carrying forebrain interneuron-specific and those carrying cardiacspecific heterozygote $\mathrm{KO}$ of $\operatorname{Scn} 1 \mathrm{a}$ were generated by the Cre-LoxP-mediated recombination. Three mice lines were used: (a) The Dlx-I12bCre line (a gift from John L. Rubenstein, UCSF, San Francisco, California, USA), in which the intergenic region of the Dlx 1 and $D l \times 2$ homeobox genes drives Cre recombinase expression in interneurons of forebrain and some other subcortical regions; (b) the MerCreMer line (Jackson Laboratory), in which the promoter of $\alpha$-myosin heavy chain drives cardiac expression of a tamoxifen-inducible Cre (MerCreMer) recombinase; (c) and the Scn1afloxed line harboring LoxP sites flanking the exon 5 of Scn $1 a$ and generated by gene targeting as previously described (25).

Forebrain interneuron-specific Scn1a-KO mice $\left(\operatorname{Scn} 1 a^{f l x /+}:\right.$ DlxI12bCre ${ }^{+}$, abbreviated $\left.\mathrm{F} /{ }^{+}: \mathrm{Dlx}-\mathrm{Cre}^{+}\right)$and their littermate controls $\left(\mathrm{F} /{ }^{+}: \mathrm{Dlx}-\mathrm{Cre}{ }^{-}\right)$were obtained by crossing Scn 1 $a^{f x / f l x}$ mice (C57BL/6) with Dlx-Cre ${ }^{+}$mice (CD1). Tamoxifen-inducible cardiac-specific Scn1a-KO (Scn $1 a^{f l x /+}: \mathrm{MerCre}^{+} \mathrm{Mer}$, abbreviated $\mathrm{F} /{ }^{+}: \mathrm{MCre}{ }^{+}$) mice were obtained by crossing $\operatorname{Scn} 1$ a $^{f l x / f l x}$ mice with MerCre ${ }^{+}$Mer mice, maintained on a C57BL/ 6 genetic background. In all the breeding of conditional $\mathrm{KO}$ mice, female Cre-carrying mice were used to reduce the number of germline recombinations. Mice were genotyped using the following Cre primers and flx primers: Cre-1 (5'-GGTTTCCCGCAGAACCTGAA-3'), Cre-2 (5'-CCATCGCTCGACCAGTTTAGT-3'), flx-311 (5'-CTTGATGGTTGAAATTCAC-3'), and flx-314 (5'-TATAGAGTGTTTAATCTCAAC-3').

Video monitoring of spontaneous convulsive seizure and death. Continuous digital videos of mice in their home cages were collected at $30 \mathrm{fps}$ using high resolution, infrared equipped, digital video cameras (Swann Communications) connected to a Dell PC workstation for data storage. Short-term (2 to 3 days) and long-term (2 week) video monitoring of sporadic deaths and spontaneous convulsive seizures was performed. Videos were reviewed, and seizures were marked and scored from 1 to 5 using the Racine scale of seizure severity (1, mouth and facial movement; 2 , head nodding; 3 , forelimb clonus; 4 , rearing with forelimb clonus; and 5 , rearing and falling with forelimb clonus) off-line by a blinded independent investigator (49). Seizure duration was defined from the beginning to end of behavioral convulsion.

Surgery. Mice underwent survival surgery to implant fine (diameter: $130 \mu \mathrm{m}$ bare; $180 \mu \mathrm{m}$ coated) silver wire EEG and ECG electrodes under ketamine/xylazine $(130 / 8.8 \mathrm{mg} / \mathrm{kg})$ anesthesia. Using aseptic technique, a midline incision was made above the skull and a second incision above the thorax. For EEG recording, 2 small cranial holes were made with a fine cutting needle above each temporal cortex. Two EEG electrodes were placed through the small cranial burr holes and fixed in place with cyanoacrylate glue and dental cement. Similarly, 1 reference electrode was placed above the cerebellum. Then a ground electrode was inserted subcutaneously over the back. For ECG recording, 2 more silver wires were tunneled subcutaneously from the head to the thoracic incision site and anchored in place with suture. One electrode was positioned in the abdominal muscle near the heart apex (below the rib cage) and the other in the muscles near the right forelimb. All electrodes were connected to a micro-connector system, and their impedances were typically less than $10 \mathrm{k} \Omega$. After electrode placement, the skin was closed with sutures and the mice were allowed to recover from surgery for 2-3 days.

Video-EEG-ECG. Simultaneous video-EEG-ECG records were collected in conscious mice on a PowerLab 8/35 data acquisition unit using LabChart 7.3.3 software (AD Instruments). All bioelectrical signals were acquired at a 1-KHz sampling rate. The EEG signals were processed off-line with a 1to $80-\mathrm{Hz}$ bandpass filter and the ECG signals with a $3-\mathrm{Hz}$ highpass filter. 
Video-EEG-ECG data collected were analyzed using Labchart software. For resting ECG data analysis, 8 hours of data were collected from 8:00 am to 4:00 pm, but only stable segments of the records were considered. Segments with movement artifacts, electrical noise, ectopic beats, or arrhythmias were excluded. Measurements of ECG intervals (P duration, QRS duration, PR, RR, and QT) and calculated rate-corrected QT (QTc) were performed using Labchart macros. To assess HRV, the coefficient of variation of HR, standard deviation of all normal R-R intervals (SDNN, index of total autonomic variability), standard deviation of normal R-R intervals ( $\mathrm{SD}$ of $\delta \mathrm{NN}$ ), and the square root of the mean square of successive differences between adjacent normal R-R intervals (RMSSD, index of short-term variations in $\mathrm{HR}$ ) were calculated. HR is the inverse of R-R interval; to avoid duplication, RR interval was not reported. For EEG analysis, electrographic seizures were defined from the beginning of rhythmic discharges (spikes, sharp waves, or slow waves) on EEG. Myoclonic seizures consisted of brief burst of spike or polyspike-wave activity on EEG associated with sudden brief involuntary contraction or contractions of muscles.

Thermal seizure induction. Mouse core body temperature was controlled using a rectal temperature probe and a heat lamp attached to a temperature controller in a feedback loop (Physitemp Instruments Inc.). Body temperature was increased by $0.5^{\circ} \mathrm{C}$ every 2 minutes until seizure occurred or a $42^{\circ} \mathrm{C}$ temperature was reached (20). Mice were immediately cooled using a small fan. To induce Racine 5 seizure in $\mathrm{F} /{ }^{+}:$Dlx-Cre ${ }^{+}$mice, cooling was delayed until 30 seconds after seizure onset.

Pharmacology. Mice were administered atropine or N-methyl scopolamine (1 mg/kg, i.p.) for selective parasympathetic blockade, propranolol ( $4 \mathrm{mg} / \mathrm{kg}$, i.p.) for selective sympathetic blockade, and combined atropine $(1 \mathrm{mg} / \mathrm{kg}$, i.p.) and propranolol (4 mg/kg, i.p.) for complete autonomic blockade. For autonomic function assessments, mice were allowed to acclimate for 15 minutes in the recording chamber, and resting video-EEG-
ECG records were continuously collected before, during, and after each pharmacological agent was administered. Peak effects of the drugs on ECG were observed around 30 minutes after injection. Changes between resting heart rate before administration of each drug and during drug peak effect period were calculated.

Statistics. Data are reported as mean \pm SD. Comparisons within groups were done by paired 2 -tailed $t$ tests and across groups by unpaired 2 -tailed $t$ tests. Differences were considered significant at $P<0.05$.

Study approval. All experimental procedures involving mice were approved by the University of Washington Institutional Animal Care and Use Committee in accordance with the guidelines of the NIH.

\section{Acknowledgments}

We thank Nicholas Poolos (Neurology, University of Washington) for technical advice and Neil M. Nathanson (Pharmacology, University of Washington) for insightful discussions. This research was supported by NIH research grants R01 NS25704 (to W.A. Catterall) and K01 NS062862 (to F. Kalume) and by a grant from the McKnight Foundation.

Received for publication October 23, 2012, and accepted in revised form January 18, 2013.

Address correspondence to: William A. Catterall, University of Washington, Box 357280, Seattle, Washington 98195-7280, USA. Phone: 206.543.1925; Fax: 206.543.3882; E-mail: wcatt@uw.edu.

Frank H. Yu's present address is: Program in Neurobiology, School of Dentistry and Dental Research Institute, Seoul National University, Seoul, Republic of Korea, 110-749.
1. Annegers JF, Coan SP. SUDEP: overview of definitions and review of incidence data. Seizure. 1999; 8(6):347-352.

2. Aurlien D, Larsen JP, Gjerstad L, Tauboll E. Increased risk of sudden unexpected death in epilepsy in females using lamotrigine: a nested, casecontrol study. Epilepsia. 2012;53(2):258-266.

3. Shorvon S, Tomson T. Sudden unexpected death in epilepsy. Lancet. 2011;378(9808):2028-2038.

4. Hitiris N, Suratman S, Kelly K, Stephen LJ, Sills GJ, Brodie MJ. Sudden unexpected death in epilepsy: a search for risk factors. Epilepsy Behav. 2007; 10(1):138-141.

5. Marini C, et al. Idiopathic epilepsies with seizures precipitated by fever and SCN1A abnormalities. Epilepsia. 2007;48(9):1678-1685.

6. Oguni H, Hayashi K, Awaya Y, Fukuyama Y, Osawa M. Severe myoclonic epilepsy in infants - a review based on the Tokyo Women's Medical University series of 84 cases. Brain Dev. 2001;23(7):736-748.

7. Dravet C, Bureau M, Oguni H, Fukuyama Y, Cokar O. Severe myoclonic epilepsy in infancy: Dravet syndrome. Adv Neurol. 2005;95:71-102.

8. Genton P, Velizarova R, Dravet C. Dravet syndrome: the long-term outcome. Epilepsia. 2011; 52(suppl 2):44-49.

9. Catarino CB, et al. Dravet syndrome as epileptic encephalopathy: evidence from long-term course and neuropathology. Brain. 2011;134(pt 10):2982-3010.

10. Dravet C, Bureau M, Genton P. Benign myoclonic epilepsy of infancy: electroclinical symptomatology and differential diagnosis from the other types of generalized epilepsy of infancy. Epilepsy Res Suppl. 1992;6:131-135.

11. Akiyama M, Kobayashi K, Yoshinaga H, Ohtsuka Y. A long-term follow-up study of Dravet syndrome up to adulthood. Epilepsia. 2010;51(6):1043-1052.

12. SkluzacekJV, Watts KP, Parsy O, Wical B, Camfield P.
Dravet syndrome and parent associations: the IDEA League experience with comorbid conditions, mortality, management, adaptation, and grief. Epilepsia. 2011;52(suppl 2):95-101.

13. Surges R, Thijs RD, Tan HL, Sander JW. Sudden unexpected death in epilepsy: risk factors and potential pathomechanisms. Nat Rev Neurol. 2009;5(9):492-504.

14. Maier SK, et al. An unexpected requirement for brain-type sodium channels for control of heart rate in the mouse sinoatrial node. Proc Natl Acad Sci US A. 2003;100(6):3507-3512.

15. Maier SK, Westenbroek RE, Schenkman KA, Feigl EO, Scheuer T, Catterall WA. An unexpected role for brain-type sodium channels in coupling of cell surface depolarization to contraction in the heart. Proc Natl Acad Sci U S A. 2002;99(6):4073-4078.

16. Gong B, Rhodes KJ, Bekele-Arcuri Z, Trimmer JS. Type I and type II $\mathrm{Na}^{+}$channel alpha-subunit polypeptides exhibit distinct spatial and temporal patterning, and association with auxiliary subunits in rat brain. J Comp Neurol. 1999;412(2):342-352.

17. Westenbroek RE, Merrick DK, Catterall WA. Differential subcellular localization of the RI and RII Na+ channel subtypes in central neurons. Neuron. 1989; 3(6):695-704.

18. Trimmer JS, Rhodes KJ. Localization of voltagegated ion channels in mammalian brain. Annu Rev Physiol. 2004;66:477-519.

19. Kalume F, Yu FH, Westenbroek RE, Scheuer T, Catterall WA. Reduced sodium current in Purkinje neurons from Nav1.1 mutant mice: implications for ataxia in severe myoclonic epilepsy in infancy. J Neurosci. 2007;27(41):11065-11074.

20. Oakley JC, Kalume F, Yu FH, Scheuer T, Catterall WA. Temperature- and age-dependent seizures in a mouse model of severe myoclonic epilepsy in infancy. Proc Natl Acad Sci U S A. 2009;106(10):3994-3999.

21. Oakley JC, Kalume F, Catterall WA. Insights into pathophysiology and therapy from a mouse model of Dravet syndrome. Epilepsia. 2011;52(suppl 2):59-61.

22. Yu FH, et al. Reduced sodium current in GABAergic interneurons in a mouse model of severe myoclonic epilepsy in infancy. Nat Neurosci. 2006; 9(9):1142-1149.

23. Han $\mathrm{S}$, et al. $\mathrm{Na}_{\mathrm{V}} 1.1$ channels are critical for intercellular communication in the suprachiasmatic nucleus and for normal circadian rhythms. Proc Natl Acad Sci U S A. 2012;109(6):E368-E377.

24. Kalume F, Oakley JC, Westenbroek RE, Scheuer T, Catterall WA. Sleep impairment and reduced excitability of GABAergic interneurons in the reticular nucleus of the thalamus in a mouse model of severe myoclonic epilepsy of infancy. SFN. 2010;255:Q18.

25. Cheah CS, et al. Specific deletion of $\mathrm{Na}_{\mathrm{v}} 1.1$ sodium channels in inhibitory interneurons causes seizures and premature death in a mouse model of Dravet syndrome. Proc Natl Acad Sci U S A. 2012; 109(36):14646-14651.

26. Chapman MG, Smith M, Hirsch NP. Status epilepticus. Anaesthesia. 2001;56(7):648-659.

27. Nashef L, So EL, Ryvlin P, Tomson T. Unifying the definitions of sudden unexpected death in epilepsy. Epilepsia. 2012;53(2):227-233.

28. Hirsch LJ, et al. Abbreviated report of the NIH/ NINDS workshop on sudden unexpected death in epilepsy. Neurology. 2011;76(22):1932-1938.

29. Stein PK, Kleiger RE. Insights from the study of heart rate variability. Annu Rev Med. 1999;50:249-261.

30. Tomson T, Ericson M, Ihrman C, Lindblad LE. Heart rate variability in patients with epilepsy. Epilepsy Res. 1998;30(1):77-83.

31. Ronkainen E, Ansakorpi H, Huikuri HV, Myllyla VV, Isojarvi JI, Korpelainen JT. Suppressed circadian heart rate dynamics in temporal lobe epilepsy. J Neurol Neurosurg Psychiatry. 2005;76(10):1382-1386.

32. Catterall WA, Kalume F, Oakley JC. $\mathrm{Na}_{v} 1.1$ channels 
and epilepsy. J Physiol. 2010;588(pt 11):1849-1859.

33. Glasscock E, Yoo JW, Chen TT, Klassen TL, Noebels JL. Kv1.1 potassium channel deficiency reveals brain-driven cardiac dysfunction as a candidate mechanism for sudden unexplained death in epilepsy. J Neurosci. 2010;30(15):5167-5175.

34. Goldman AM, Glasscock E, Yoo J, Chen TT, Klassen TL, Noebels JL. Arrhythmia in heart and brain: KCNQ1 mutations link epilepsy and sudden unexplained death. Sci Transl Med. 2009;1(2):2ra6

35. Liguori R, Avoni P, Baruzzi A, Di Stasi V, Montagna P. Familial continuous motor unit activity and epilepsy. Muscle Nerve. 2001;24(5):630-633.

36. Zuberi SM, et al. A novel mutation in the human voltage-gated potassium channel gene (Kv1.1) associates with episodic ataxia type 1 and sometimes with partial epilepsy. Brain. 1999;122(pt 5):817-825.

37. Glasscock E, Qian J, Kole MJ, Noebels JL. Transcompartmental reversal of single fibre hyperexcitability in juxtaparanodal Kv1.1-deficient vagus nerve axons by activation of nodal KCNQ channels.
J Physiol. 2012;590(pt 16):3913-3926.

38. Langan Y, Nashef L, Sander JW. Sudden unexpected death in epilepsy: a series of witnessed deaths. I Neurol Neurosurg Psychiatry. 2000;68(2):211-213.

39. Devinsky O. Sudden, unexpected death in epilepsy. NEngl J Med. 2011;365(19):1801-1811.

40. Faingold CL, Randall M, Tupal S. DBA/1 mice exhibit chronic susceptibility to audiogenic seizures followed by sudden death associated with respiratory arrest. Epilepsy Behav. 2010;17(4):436-440.

41. Faingold CL, Tupal S, Randall M. Prevention of seizure-induced sudden death in a chronic SUDEP model by semichronic administration of a selective serotonin reuptake inhibitor. Epilepsy Behav. 2011; 22(2):186-190

42. So EL. What is known about the mechanisms underlying SUDEP? Epilepsia. 2008;49(suppl 9):93-98.

43. Nashef L, Ryvlin P. Sudden unexpected death in epilepsy (SUDEP): update and reflections. Neurol Clin. 2009;27(4):1063-1074.

44. Nashef L, Garner S, Sander JW, Fish DR, Shorvon SD.
Circumstances of death in sudden death in epilepsy: interviews of bereaved relatives. J Neurol Neurosurg Psychiatry. 1998;64(3):349-352.

45. Kloster R, Engelskjon T. Sudden unexpected death in epilepsy (SUDEP): a clinical perspective and a search for risk factors. J Neurol Neurosurg Psychiatry. 1999;67(4):439-444.

46. Surges R, Henneberger C, Adjei P, Scott CA, Sander JW, Walker MC. Do alterations in inter-ictal heart rate variability predict sudden unexpected death in epilepsy? Epilepsy Res. 2009;87(2-3):277-280.

47. Delogu AB, et al. Electrical and autonomic cardiac function in patients with Dravet syndrome. Epilepsia. 2011;2:55-58.

48. Nobili L, Proserpio P, Rubboli G, Montano N, Didato G, Tassinari CA. Sudden unexpected death in epilepsy (SUDEP) and sleep. Sleep Med Rev. 2011; 15(4):237-246.

49. Racine RJ. Modification of seizure activity by electrical stimulation. II. Motor seizure. Electroencephalogr Clin Neurophysiol. 1972;32(3):281-294. 